\title{
Analisa Kepuasan Mahasiswa terhadap Kualitas Pelayanan Pendidikan
}

\author{
Ni Luh Anik Puspa Ningsih, Dewa Ayu Putu Niti Widari dan I Made Artawan \\ Universitas Warmadewa, Denpasar-Bali, Indonesia \\ *kinapuspa168@gmail.com
}

How to cite (in APA style):

Ningsih, N, L, A, P., Widari, D, A, P, N., Artawan, I, M. (2020). Analisa Kepuasan Mahasiswa terhadap Kualitas Pelayanan Pendidikan. 19(1), pp.24-29. http://dx.doi.org/10.22225/we.19.1.1403.24-29

\begin{abstract}
During the learning process, students have experience with educational services at the University. This experience will create a perspective on the quality of education services provided. This will be related to the level of student satisfaction. This level of satisfaction will made an opinions. That generally will quickly spread, to family, friends and society. Bad opinion will affect the University's image, so it is important to analyze student satisfaction. A survey are held to gain information about student satisfaction.. This research was conducted at Warmadewa University, a private university in Denpasar, Bali. Survey results are summarized in the index of student satisfaction with the quality of education services at Warmadewa University. Based on the dimensions of service quality, namely tangibles, reliability, empathy, responsiveness, assurance students feel "satisfied". The overall survey results show that students assess the quality of education services at a "satisfying" level.
\end{abstract}

Keywords: Student Satisfaction; Educational Service Quality

\begin{abstract}
Abstrak-Selama proses pembelajaran, mahasiswa memiliki pengalaman terkait pelayanan pendidikan di Universitas. Pengalaman ini menciptakan persepsi terhadap kualitas pelayanan pendidikan yang akan membentuk kepuasan bagi mahasiswa. Tingkat kepuasan tertentu akan membentuk opini. Ini akan menyebar dengan cepat, pada keluarga, teman dan masyarakat. Persepsi yang buruk akan mempengaruhi citra Universitas. Tujuan dari penelitian ini untuk menganalisa tingkat kepuasan mahasiswa terhadap kualitas pelayanan pendidikan di Universitas. Populasi penelitian ini adalah seluruh mahasiswa aktif

Penelitian ini dilakukan di Universitas Warmadewa, Denpasar, Bali. Penelitian dilakukan dengan metode survey. Hasil survey terangkum dalam indeks kepuasan mahasiswa terhadap kualitas pelayanan pendidikan di Universitas Warmadewa. Berdasarkan dimensi kualitas layanan yaitu bukti fisik, kehandalan, empati, daya tanggap dan jaminan, mahasiswa merasa "puas". Hasil survey keseluruhan menunjukkan bahwa mahasiswa menilai kualitas layanan pendidikan pada tingkat "memuaskan"
\end{abstract}

Kata kunci : Kepuasan Mahasiswa ; Kualitas Pelayanan Pendidikan

\section{PENDAHULUAN}

Pendidikan di Indonesia dihadapkan pada tantangan global yang tidak dapat dihindari, semua pihak dituntut mampu bertahan (survive) dalam menghadapi kondisi tersebut. Perguruan Tinggi (PT) baik negeri maupun swasta dituntun membuat standar-standar tentang pengelolaan dan pelayanan untuk meningkatkan kinerja agar tidak tertinggal dalam menghadapi globalisasi dan pasar bebas. Pemerintah terus berupaya meningkatkan kinerja PT dengan mendorong PT agar mengadopsi standar ISO 9001 ke dalam proses-proses yang berlangsung di PT. Hal itu dilakukan oleh pemerintah agar PT dapat menghasilkan jasa pendidikan yang unggul dan melahirkan lulusan dengan mutu yang baik sesuai standar baku yang berlaku secara internasional.

Dalam proses belajar mengajar perkuliahan, mahasiswa akan berinteraksi dengan pelayanan akademik pada Universitas Warmadewa. Pengalaman selama studi termasuk tingkat kepuasan yang dirasakan menjadi sangat bermakna dan akan memperngaruhi penciptaan opini yang akan dengan cepat dibagikan kepada keluarga, teman dan masyarakat yang secara teori disebut dengan $W$ ord of Mouth (WOM). Penciptaan opini berdasarkan pengalaman yang dirasakan akan membentuk persepsi dan penilaian. Pengalaman mahasiswa dalam proses perkuliahan dan pelayanan administrasi yang dirasakan akan mempengaruhi penciptaan tingkat kepuasan mahsiswa (Istiningtyas, 2015). Kualitas pelayanan di Universitas sangat menentukan tingkat kepuasan yang dirasakan mahasiswa. Apabila persepsi mahasiswa terhadap kualitas pelayanan semakin baik dan positif, maka kepuasan mahasiswa juga akan meningkat. Apabila perpsepsi ini kurang baik (negatif) maka kepuasan maha- 
siswa akan semakin rendah (Bulkia, 2018). Hal ini menjadikan penting untuk melakukan analisa terhadap kepuasan mahasiswa terhadap kualitas pelayanan pendidikan. (Dedek Kurniawan Gultom, Ginting, \& Sembiring, 2014) memberikan dukungan bahwa Bukti langsung, kehandalan, ketanggapan, jaminan dan empati pada pelayanan pendidikan menjadi tolak ukur bagi mahasiswa dan memberikan dampak pada tingkat kepuasan mahasiswa.

Universitas Warmadewa sebagai salah satu Perguruan Tinggi Swasta (PTS) dituntut mampu bersaing dalam hal mutu pendidikan dan kualitas pelayanan akademik. Universitas Warmadewa mengupayakan standar pelayanan dan tata kelola pendidikan yang berlangsung mendapat pengakuan dari dunia internasional, tercermin dari visi Universitas Warmadewa "Menjadi pusat pendidikan dan pengembangan ilmu pengetahuan dan teknologi (IPTEK) yang bermutu, berintegritas, berwawasan lingkungan kepariwisataan dan kompetitif secara global di tahun 2034. Penting bagi Universitas untuk melakukan penilaian terhadap layanan pendidikan yang diberikan untuk mengetaui harapan dari responden dan sebagai bahan evauasi terhadap pelayanan pendidikan yang diberikan.

Berdasarkan uraian tersebut, sangat diperlukan analisa untuk mengukur tingkat kepuasan mahasiswa terhadap kualitas pelayanan akademik yang disediakan oleh Universitas Warmadewa. dalam upaya meningkatkan mutu dan kualitas pelayanan berbasis kualitas kinerja good university governance.

\section{KAJIAN PUSTAKA}

\section{Kualitas Pelayanan}

Kualitas Pelayanan oleh (Parasuraman, Berry, \& Zeithaml, 1985) dijelaskan dengan model service quality (SERVQUAL). Layanan jasa bersifat intangible sehingga difokuskan pada upaya menurunkan tingkat kesenjangan komunikasi dan pemahaman antara penyedia jasa dan pelanggan. Hal ini akan berdampak pada persepsi terhadap kualitas layanan. Apabila apa yang dikomunikasikan berbeda dengan apa yang diterima atau diberikann oleh penyedia jasa, maka akan menimbulkan gap.

Terdapat beberapa faktor sebagai pemicu buruknya kualitas layanan yang diberikan oleh penyedia, diantaranya jasa diproduksi dan dikonsumsi secara bersamaan, memperlakukan konsumen yang berbeda dengan cara yang sama, perluasan atau pengembangan layanan secara berlebihan, orientasi bisnis hanya pada target jangka pendek (Tjiptono \& Gregorius, 2011).

Pengkuran terhadap kualitas layanan dapat mempergunakan 5 (lima) dimensi utama dari SERVQUAL (Zeithaml, A, Jo, \& Gremler, 2009) yaitu, bukti fisik, kehandalan, empati/kepedulian, daya tanggap dan jaminan. Secara spesifik Johnson (1998) menjelaskan dimensi kualitas layanan Bukti fisik (Tangibles) dapat dirasakan melalui tampilan secara fisik fasilitas layanan, peralatan/ perlengkapan, sumber daya manusia (SDM) ; Kehandalan (Reliability) berupa kemampuan perusahaan dalam menyampaikan layanan yang dijanjikan secara akurat ; Daya Tanggap (Responsiveness) upaya memberikan pelayanan yang baik kepada pelanggan ; Jaminan (Assurance) yaitu bentuk kepercayaan yang dapat diberikan ; Kepedulian (Emphaty) yaitu bentuk kepedulian dan perhatian perusahaan/penyedia layanan.

\section{Kepuasan Pelanggan (Mahasiswa)}

Kepuasan pelanggan dijelaskan sebagai suatu nilai yang dihasilkan suatu produk atau jasa setelah dinikmati oleh pelanggan. Nilai ini dibentuk melalui dari tercapainya harapan (keinginan) konsumen terhadap suatu produk atau jasa. Kepuasan pelanggan merupakan situasi kognitif dimana konsumen merasakan bahwa apa yang mereka korbankan sebanding dengan yang diterima (Howard \& Sheth ; (Tjiptono \& Gregorius, 2011)

Adapun manfaat secara spesifik yang ditimbulkan apabila kepuasan pelanggan tercapai, antara lain : meningkatkan loyalitas pelanggan, potensi sumber pendapatan masa depan (rebuying, crossselling, up selling), menekan biaya transaksi pelanggan, meningkatkan toleransi harga oleh palnggan, rekomendasi penyebaran infromasi (word of mouth) yang positif (Tjiptono \& Gregorius, 2011)

Kepuasan pelanggan itu dapat diukur dengan berbagai macam metode (Kotler, 2000); (Tjiptono \& Gregorius, 2011) yaitu : (1) sistem keluhan dan saran (2) Ghost shopping dengan memperkerjakan beberapa orang untuk berperan atau bersikap sebagai pembeli potensial, untuk mengamati dan melaporkan kekuatan dan kelemahan produk perusahaan dan pesaing (3) mengamati cara penanganan setiap keluhan. (4) Lost customer analysis, menghubungi para pelanggan yang telah 
berhenti membeli untuk mengetahui kelemahan produk dan keunggulan pesaing (5) Survei kepuasan pelangga, dilakukan dengan penelitian survai, baik melalui pos, telepon maupun wawancara langsung (McNeal dan Lamb dalam (Peterson \& Wilson, 1992).

\section{METODE}

Penelitian ini adalah penelitian survei. Secara umum, pengertian survei dibatasi pada penelitian yang datanya dikumpulkan dari sampel atas populasi untuk mewakili seluruh populasi (Sugiyono, 2015). Penelitian ini dilakukan pada Universitas Warmadewa, Denpasar, Bali. Target populasi dalam laporan ini adalah seluruh mahasiswa aktif semester genap tahun 2018 yang terdiri dari mahasiswa sarjana (S1) dan pascasarjana (S2) di Universitas Warmadewa. Populasi berjumlah 10.490 mahasiswa. Jumlah sampel ditentukan berdasarkan kuota $6 \%$ dari keseluruhan poplulasi, diperoleh sejumlah 629 orang mahasiswa. Penentuan sampel dengan stratified proporsional random sampling dengan memperhatikan strata di Universitas.

Kepuasan Mahasiswa

Variable ini diukur dengan Indeks Kepuasan. Indeks ini adalah ukuran gabungan untuk suatu variable. Pengukuran kepuasan melalui beberapa dimensi atau aspek. Dalam penelitian ini setiap pernyataan diberi bobot (weight) yang sama

Kualitas Layanan Pendidikan

Variabel ini diukur yang digunakan untuk mengukur indeks kualitas layanan, (Zeithaml et al., 2009) dengan lima dimensi yaitu Tangibles (Bukti Langsung), Reliability (Keandalan), Emphaty (Empati), Responsiveness (Ketanggapan) dan Assurance (Jaminan) jelaskan

Indikator inilah yang berperan dalam penciptaan kualitas layanan yang Secara lebih jelas men-

Data skor yang diberikan mahasiswa terkait tingkat kepuasan yang dirasakan pada setiap aspek kualitas pelayanan diolah untuk memperoleh tingkat kepuasan rata-rata. Persepsi terhadap kualitas pelayanan pendidikan mempergunakan skala pengukuran 1 sampai 4. Tingkat kepuasan mahasiwa diklasifikan dengan mempergunakan Indeks Kepuasan Konsumen (Fornell, Johnson, \& Anderson, 1996). Indeks ini adalah Indeks Kepuasan Mahasiswa yang dibuat dengan menghitung grand mean (rerata dari rata-rata). Pengolahan data dilakukan dengan bantuan Microsoft Excel. Berdasarkan nilai rata-rata tersebut dapat disusun tabel klasifikasi skala kepuasan mahasiswa terhadap pelayanan pendidikan dengan kriteria ; rentang skor $1.00-1.75$ (kurang memuaskan), 1.76 - 2.50 (cukup memuaskan ), $2.51-3.25$ (memuaskan), $3.26-4.00$ (sangat memuaskan) mengacu pada laporan survei (Badan Penjaminan Mutu (BPM), 2016).

Analisis data menggunakan statistik deskriptif, membuat tabel, grafik (bar chart, pie diagram) dengan tujuan untuk memberikan gambaran tingkat kepuasan mahasiswa terhadap kualitas pelayanan pendidikan.

\section{HASIL PENELITIAN DAN PEMBAHASAN}

\section{Karakteristik Responden}

Dalam proses survei, kuesioner diberikan kepada responden untuk diisi terkait pengalaman layanan pendidikan yang dirasakan. Dari 629 kuesioner yang disebar pada responden, hanya 579 kuesioner yang kembali. berikut,

Karakteristik responden dapat dijelaskan berdasarkan jenis kelamin, usia dan fakultas sebagai

1) Respon yang diberikan oleh responden berdasarkan jenis kelamin

Adapun klasifikasi responden berdasarkan jenis kelamin dapat dijelaskan bahwa komposisi responden dalam persentase yang nyaris berimbang, yaitu 51\% (298 orang) perempuan dan 49\% (281 orang) laki-laki.

Respon yang diberikan oleh responden berdasarkan usia

Berdasarkan usia, responden dominan bersana pada usia 20 tahun (205 orang), secara mendetail disajikan pada gambar berikut ; 


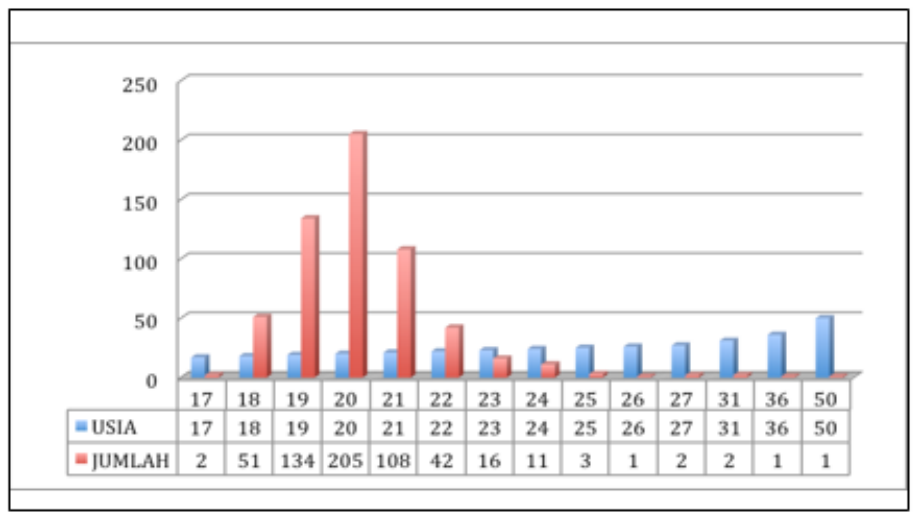

Gambar 1. Responden berdasarkan Usia

Respon yang diberikan oleh responden dilihat dari fakultas

Adapun sebaran respon mahasiswa berdasarkan asal fakultas didominasi oleh Fakultas Ekonomi yaitu 38\% (221 orang) yang paling sedikit adalah pascasarjana yaitu 2\% (9 orang) detail dapat dilihat pada gambar berikut .

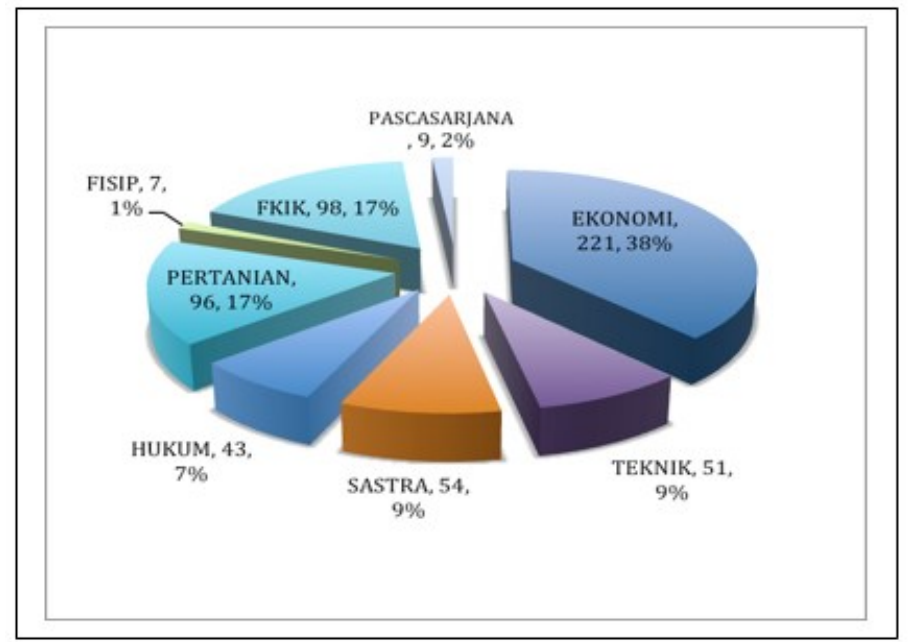

Gambar 2. Responden berdasarkan Fakultas

Indeks Kepuasan Mahasiswa

Penilaian responden (mahasiswa) terhadap kualitas pelayanan pendidikan di Universitas Warmadewa akan membentuk indek kepuasan mahasiswa. Adapun indeks tersebut disajikan pada tabel berikut ;

Tabel 1

Indeks kepuasan mahasiswa terhadap kualitas pelayanan pendidikan di Universitas Warmadewa

\begin{tabular}{cccc}
\hline No & Dimensi Kualitas Layanan & Deskripsi Kualitas Pelayanan Pendidikan & Nilai \\
\hline 1 & Tangibles & Sarana dan Prasarana Pendidikan & 3,06 \\
2 & Reliability & Kehandalan Karyawan & 3,11 \\
3 & Emphaty & Pemahaman Karyawan terhadap kepentingan & 3,19 \\
& & Mahasiswa & \\
4 & Responsiveness & Sikap cepat tanggap Karyawan & 3,10 \\
5 & Assurance & Universitas Warmadewa merupakan lembaga & 3,30 \\
& & yang & \\
& Rata-Rata & terpercaya bagi mahasiswa & 3,15 \\
\hline
\end{tabular}


Berdasarlan Tabel 1, dapat dijelaskan bahwa secara keseluruhan, mahasiswa merasa "puas" atas pelayanan pendidikan yang diberikan pada Universitas Warmadewa. Dengan kalimat berbeda dapat dijelaskan bahwa responden (mahasiswa) menilai kualitas pelayanan pendidikan di Universitas Warmadewa pada level "memuaskan".

Mahasiswa menilai aspek Tangibles yaitu sarana dan prasarana pendidikan di Universitas Warmadewa dengan rata-rata penilaian 3.06. Mahasiswa merasa "puas" atas aspek ini. Aspek lain yang terkategori dalam Pelayanan Pendidikan adalah Reliability yaitu kehandalan karyawan pada Universitas Warmadewa dalam memberikan pelayanan pendidikan kepada mahasiswa, mahasiswa mempersepsikan "memuaskan" dengan rata-rata penilaian 3.11. Aspek selanjutnya adalah Emphaty yaitu pemahaman karyawan di Universitas Warmadewa terhadap kepentingan mahasiswa, juga dinilai "memuaskan" oleh mahasiswa dengan rata-rata penilaian 3.19. Aspek yang tidak kalah pentingnya dalam pelayanan pendidikan adalah Responsiveness yaitu sikap cepat tanggap karyawan Universitas Warmadewa kepada mahasiswa, penilaian rata-rata mahasiswa pada aspek ini adalah 3.10 dengan kalimat lain mahasiwa merasa "puas" akan layanan ini. Aspek berikutnya adalah aspek Assurance yaitu Universitas Warmadewa merupakan lembaga yang terpercaya bagi mahasiswa, dengan rata-rata nilai 3.29 yang bermakna bahwa mahasiswa mempersepsikan layanan ini "memuaskan"

Secara rinci penilaian atas masing-masing dimensi dari kualitas pelayanan pendidikan, disajikan pada gambar berikut:

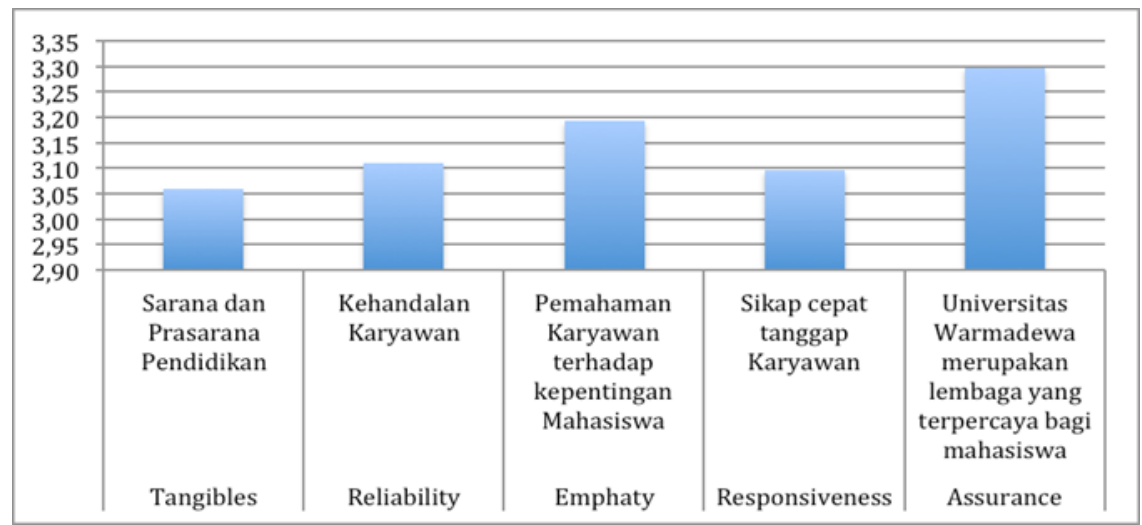

Gambar 3

Tingkat Kepuasan Mahasiswa terhadap Pelayanan Pendidikan di Un iversitas Warmadewa

\section{SIMPULAN}

Berdasarkan hasil dan pembahasan yang telah diuraikan, dapat disimpulkan bahwa Indeks Kepuasan Mahasiswa menunjukkan nilai 3.15, yang bermakna bahwa mahasiswa sebagai responden menilai kualitas pelayanan pendidikan berada pada level "memuaskan". Dengan bahasa yang berbeda dapat dijelaskan bahwa mahasiswa merasa "puas" atas pelayanan pendidikan yang dirasakan, atau yang diberikan oleh Universitas Warmadewa.

Secara spesifik mahasiswa memberikan penilaian "memuaskan" atas semua indikator dari kualitas pelayanan pendidikan. Mahasiswa menilai aspek Tangible yaitu Sarana dan Prasarana Pendidikan dengan rata-rata penilaian 3.06 ; aspek Reliability yaitu Kehandalan Karyawan dengan ratarata penilaian 3.11 ; aspek Emphaty yaitu Pemahaman Karyawan terhadap Kepentingan Mahasiwa, dengan rata-rata penilaian 3.19 ; aspek Responsiveness yaitu Sikap Cepat Tanggap Karyawan, dengan rata-rata penilaian rata-rata 3.10 ; aspek Assurance yaitu Universitas Warmadewa merupakan Lembaga yang terpercaya bagi Mahasiswa dinilai rata-rata 3.29.

\section{DAFTAR PUSTAKA}

Badan Penjaminan Mutu (BPM). (2016). Laporan Monev Kepuasan Mahasiswa terhadap Layanan Kemahasiswaan Semester Genap 2015/2016. Universitas 17 Agustus 1945.

Bulkia, S. (2018). Pengaruh Kualitas Pelayanan terhadap Kepuasan Mahasiwa. Jurnal Ilmiah Manajemen AT- 
TADBIR, 2(1), 49-58. Retrieved from https://ojs.uniska-bjm.ac.id/index.php/jurnalattadbir/article/ view/1191

Dedek Kurniawan Gultom, Ginting, P., \& Sembiring, B. K. (2014). Pengaruh Bauran Pemasaran Jasa Dan Kualitas Pelayanan Terhadap Kepuasan Mahasiswa Program Studi Manajemen Fakultas Ekonomi Universitas Muhammadiyah Sumatera Utara. Jurnal Manajemen \& Bisnis, 14(1), 21-33. Retrieved from http:/jurnal.umsu.ac.id/index.php/mbisnis/article/view/113

Fornell, C., Johnson, M. ., \& Anderson, E. . (1996). The American Customer Satisfaction Index, Nature Purpose and Finding. Journal of Marketing, 60, 7-18. Retrieved from https:// pdfs.semanticscholar.org/47fd/e97772657c1c8691fad838c7667f4f22f51b.pdf

Istiningtyas, L. (2015). Survei Kepuasan Alumni terhadap Kualitas Pelayanan Program Studi Psikologi Islam Fakultas Ushuluddin dan Pemikiran Islam UIN Raden Fatah Palembang. Jurnal Psikologi Islam, 1 (2), 79-93. Retrieved from http://jurnal.radenfatah.ac.id/index.php/psikis/article/view/570

Kotler, P. (2000). Marketing Management : The Determinant of Perceived Service Quality and its Relationship with Satisfaction. Journal of Service Marketing, 217-229.

Parasuraman, A. P., Berry, L. L., \& Zeithaml, V. A. (1985). A Conceptual Model of Service Quality and its Implication for Future Research (SERVQUAL). Journal of Marketing, 49, 41-50. Retrieved from https://www.researchgate.net/ publication/225083670_A_Conceptual_Model_of_Service_Quality_and_its_Implication_for_Future_Resea rch_SERVQUAL

Peterson, R. A., \& Wilson, W. . (1992). Measuring customer satisfaction: Fact and artifact. Journal of the Academy of Marketing Science, 20. Retrieved from https://link.springer.com/article/10.1007/ BF02723476

Sugiyono. (2015). Metode Penelitian Pendidikan (Pendekatan Kuantitatif, Kualitatid dan R\&D). Bandung: CV. Alfabeta.

Tjiptono, F., \& Gregorius, C. (2011). Service Quality \& Satisfation Edisi 3. Yogyakarta: Andi.

Zeithaml, V., A, B., Jo, M., \& Gremler, D. D. (2009). Service Marketingn Integrated Customer Focus Across the Firm. United Kingdom: Mc Graw-Hill Education. 